\section{JTI}

JOURNAL OF

TRAUMA AND INJURY

\title{
Epidemiology and Incidence of Orthopedic Fractures in the Military of the Republic of Korea
}

\author{
Sung-Jin An, M.D. ${ }^{1}$, Sang Hyun Lee, M.D. ${ }^{2}$, Gi-Ho Moon, M.D. ${ }^{1}$ \\ ${ }^{1}$ Department of Orthopedic Surgery, Armed Forces Capital Hospital, Seongnam, Korea \\ ${ }^{2}$ Department of Orthopedic Surgery, Pusan National University Hospital, Pusan National \\ University School of Medicine, Busan, Korea
}

Received: September 7, 2020

Revised: October 20, 2020

Accepted: October 24, 2020

\section{Correspondence to}

Gi-Ho Moon, M.D.

Department of Orthopedic Surgery, Armed Forces Capital Hospital, 81

Saemaeul-ro 177beon-gil, Bundang-gu, Seongnam 13574, Korea

Tel: +82-31-725-6114

Fax: +82-31-706-0987

E-mail:m11110@naver.com

Purpose: Fractures are common in the military population, but limited studies have investigated the incidence of fractures among Korean military personnel. Hence, this study aimed to clarify this issue.

Methods: Eligible subjects were patients who had sustained a fracture and were registered in the N-DEMIS (the medical records system of participating hospitals) from June 2017 to May 2019. Fractures were categorized according to the fracture site, patients' age, sex, and type of duty.

Results: In total, 23,687 patients with 23,981 fractures were included. There were 216 patients with multiple fractures, of whom 156 had fractures at two sites, 42 had fractures at three sites, and $18 \mathrm{had}$ fractures at four sites. Of the 23,687 patients, 23,340 were men and 347 were women. The incidence of fractures in men and women was $12.96 \mathrm{per}$ 1,000 person-years and 0.19 per 1,000 person-years, respectively. In terms of the broad location of fractures, the percentage of fractures was the highest in the hand, followed by the foot and lower leg. When the location of fractures was analyzed more specifically, the percentage of fractures was the highest in the phalanx (thumb and fingers), followed by the ankle and metacarpal bones.

Conclusions: Hand, foot, ankle, and wrist fractures were the most commonly encountered fractures in the Korean military population. To prevent the loss of combat power due to non-battle-related injuries, thorough preparation is necessary, including protective equipment and preliminary training for areas with a high frequency of fracture occurrence.

Keywords: Military; Fracture; Incidence; Epidemiology; Fingers 


\section{INTRODUCTION}

Fractures sustained by both military personnel and civilians are widely prevalent and costly [1]. Activities, circumstances, and medical conditions also affect the types of fractures in both groups [2]. However, previous studies have shown that military personnel are more prone than civilians to sustaining anterior cruciate ligament and Achilles tendon injuries [3]. Another study has shown that the difference in the rate of musculoskeletal injuries, such as fractures, may be explained by the age and range of activities required for military personnel compared with civilians [4]. This study aimed to identify the distribution and incidence rate of fractures in the military population in Korea.

\section{METHODS}

From June 2017 to May 2019, patients from the annual population of 600,000 military personnel who sustained a fracture and were registered in the N-DEMIS were studied. Patients in whom fractures occurred at sites other than the extremities and spine, those in whom the sites of fractures were not precisely identified, and those who sustained fractures before the study period were excluded. Fractures were categorized according to the site at which they occurred (the upper extremity, lower extremity, spine, and pelvis). Upper extremity fractures were classified into fractures of the humerus, scapula, clavicle, forearm, and hand, and lower extremity fractures were classified into fractures of the femur, lower leg, patella, and foot (as the broad categorization). Fractures in the humerus, forearm, femur, and lower leg were further subclassified into the proximal, middle (shaft), and distal fractures (as the narrow categorization). Factures in the hand were further classified into the carpal bone, metacarpal bone, and phalanx and those in the foot were further classified into the tarsal, metatarsal, and phalanx (as the second categorization). The patients were divided into eight groups according to age: $<20$ years, $20-29$ years, $30-39$ years, $40-49$ years, and $\geq 50$ years. They were also divided into three groups according to the branch of service (Army, Navy, or Air Force).

\section{RESULTS}

A total of 23,687 patients, from an annual average of 600,000 military personnel, sustained fractures. There were 23,340 men and 347 women, with an incidence rate

Table 1. Epidemiology and incidence rate of fractures in Korean military personnel

\begin{tabular}{|c|c|c|}
\hline Injury anatomic location & Total $(n=23,981)$ & $\begin{array}{c}\text { Incidence }(1,000 \\
\text { person-year) }\end{array}$ \\
\hline \multicolumn{3}{|l|}{ Upper extremity } \\
\hline \multicolumn{3}{|l|}{ Humerus } \\
\hline Proximal & $114(0.47)$ & 0.09 \\
\hline Shaft & $322(1.34)$ & 0.26 \\
\hline Distal & $79(0.32)$ & 0.06 \\
\hline Scapula & $83(0.34)$ & 0.06 \\
\hline Clavicle & $1,136(4.73)$ & 0.94 \\
\hline \multicolumn{3}{|l|}{ Forearm } \\
\hline Proximal & $817(3.40)$ & 0.68 \\
\hline Shaft & $199(0.82)$ & 0.16 \\
\hline Distal & $1,492(6.22)$ & 1.24 \\
\hline \multicolumn{3}{|l|}{ Hand } \\
\hline Carpal & $2,047(8.53)$ & 1.71 \\
\hline Metacarpal & 2,361 (9.84) & 1.96 \\
\hline Phalanx & $5,653(23.57)$ & 4.71 \\
\hline \multicolumn{3}{|l|}{ Lower extremity } \\
\hline \multicolumn{3}{|l|}{ Femur } \\
\hline Proximal & $144(0.60)$ & 0.12 \\
\hline Shaft & $156(0.65)$ & 0.13 \\
\hline Distal & $42(0.17)$ & 0.03 \\
\hline \multicolumn{3}{|l|}{ Lower leg } \\
\hline Proximal & $245(1.02)$ & 0.21 \\
\hline Shaft & $417(1.73)$ & 0.34 \\
\hline Distal & 3,332 (13.8) & 2.77 \\
\hline Patella & $401(1.67)$ & 0.33 \\
\hline Foot & $1,022(4.26$ & 0.85 \\
\hline Tarsal & $1,869(7.79)$ & 1.55 \\
\hline Metatarsal & $1,795(7.48)$ & 1.49 \\
\hline \multicolumn{3}{|l|}{ Phalanx } \\
\hline Spine & $156(0.65)$ & 0.13 \\
\hline Pelvis & $99(0.41)$ & 0.08 \\
\hline
\end{tabular}

Values are presented as number (\%). 
of 12.96 and 0.19 per 1,000 person-years, respectively. The fractures were classified by the site, and the number fractures at each specific site is shown in Table 1.

In the broad categorization, involving a broad classification of fracture location, the percentage of fractures was the highest in the hands, followed by the lower leg, and foot. In the second categorization, with a more specific classification, the percentage of fractures was the highest in the phalanx (thumb and fingers), followed by the ankle and metacarpus, with incidence rates of 4.71, 2.77, and 1.96 , respectively, per 1,000 person-years.

Men accounted for $98.54 \%$ of the patients with fractures $(n=23,340)$ and women accounted for $1.46 \%$ $(n=347)$. Fractures in women most often occurred in the ankles, followed in descending order by the phalanx (thumb and fingers), phalanx (toes), metatarsal bones, and wrist. Fractures among men most often occurred in the phalanx (thumb and fingers), followed in order by the ankles, metacarpal bone, carpal bone, and metatarsal bone (Table 2).

The mean age was 22.9 years for men and 33.6 years for women. Overall, $90.21 \%$ of the military population was under 30 years of age. Ankle fractures in the patients most often occurred in the 30-39 age group, while finger fractures frequently occurred in other age groups. The two most common locations of fractures in every age group were the phalanx (thumb and fingers) and ankle. Metacarpal bone fractures were the third most common fracture type in those $<30$ years, while the third most common fracture site in those $\geq 30$ was the phalanx (toe) (Table 3).

The Army accounted for $85.7 \%$ of patients $(n=20,307)$, the Navy for $8.4 \%(n=1,985)$, and the Air Force for $5.9 \%$ $(\mathrm{n}=1,395$ patients). These groups had fracture incidence rates of $14.1,9.92$, and 9.38, respectively, per 1,000 person-years, with the highest incidence rate found in the Army. In the Army and Navy, the most common site of fracture incidence was the phalanx (thumb and fingers), followed in descending order by the ankles and metacarpal bones. In the Air Force, the phalanx (thumb and fingers) was the most common site, followed in descending order by the ankles and carpal bones.

\section{DISCUSSION}

The results showed that men in the military population had a fracture incidence rate of 12.96 per 1,000 person-years, and women in the military population had a

Table 2. Distribution of fractures by sex in Korean military personnel

\begin{tabular}{|c|c|c|}
\hline Injury anatomic location & Male & Female \\
\hline \multicolumn{3}{|l|}{ Upper extremity } \\
\hline \multicolumn{3}{|l|}{ Humerus } \\
\hline Proximal & $110(0.44)$ & $4(0.02)$ \\
\hline Shaft & $317(1.34)$ & $5(0.02)$ \\
\hline Distal & $77(0.28)$ & $2(0.01)$ \\
\hline Scapula & $81(0.35)$ & $2(0.01)$ \\
\hline Clavicle & $1,129(4.76)$ & $7(0.03)$ \\
\hline \multicolumn{3}{|l|}{ Forearm } \\
\hline Proximal & $795(3.34)$ & $22(0.09)$ \\
\hline Shaft & $195(0.81)$ & $4(0.02)$ \\
\hline Distal & $1,457(6.13)$ & $35(0.14)$ \\
\hline \multicolumn{3}{|l|}{ Hand } \\
\hline Carpal & $2,030(8.43)$ & $17(0.07)$ \\
\hline Metacarpal & 2,347 (9.76) & $14(0.05)$ \\
\hline Phalanx & $5,596(23.32)$ & $57(0.24)$ \\
\hline \multicolumn{3}{|l|}{ Lower extremity } \\
\hline \multicolumn{3}{|l|}{ Femur } \\
\hline Proximal & $138(0.56)$ & $6(0.02)$ \\
\hline Shaft & $148(0.61)$ & $8(0.03)$ \\
\hline Distal & $38(0.14)$ & $4(0.02)$ \\
\hline \multicolumn{3}{|l|}{ Lower leg } \\
\hline Proximal & $242(1.00)$ & $3(0.01)$ \\
\hline Shaft & $413(1.72)$ & $4(0.02)$ \\
\hline Distal & $3,272(13.71)$ & $60(0.25)$ \\
\hline Patella & $396(1.65)$ & $5(0.02)$ \\
\hline \multicolumn{3}{|l|}{ Foot } \\
\hline Tarsal & $999(4.20)$ & $21(0.08)$ \\
\hline Metatarsal & $1,823(7.59)$ & $46(0.19)$ \\
\hline Phalanx & $1,749(7.38)$ & $46(0.19)$ \\
\hline Spine & $155(0.63)$ & $1(0.00)$ \\
\hline Pelvis & $96(0.39)$ & $3(0.01)$ \\
\hline Total & 23,617 (98.48) & $364(1.52)$ \\
\hline
\end{tabular}

Values are presented as number (\%). 
Table 3. Distribution according to age

\begin{tabular}{|c|c|c|c|c|c|}
\hline Injury anatomic location & $<20$ & $20-29$ & $30-39$ & $40-49$ & $\geq 50$ \\
\hline \multicolumn{6}{|l|}{ Upper extremity } \\
\hline \multicolumn{6}{|l|}{ Humerus } \\
\hline Proximal & $6(0.03)$ & $68(0.26)$ & $13(0.06)$ & $20(0.05)$ & $8(0.03)$ \\
\hline Shaft & $24(0.10)$ & $289(1.2)$ & $11(0.05)$ & $3(0.01)$ & $0(0.00)$ \\
\hline Distal & $10(0.04)$ & $58(0.23)$ & $2(0.01)$ & $3(0.01)$ & $0(0.00)$ \\
\hline Scapula & $5(0.02)$ & $57(0.22)$ & $13(0.06)$ & $7(0.03)$ & $6(0.03)$ \\
\hline Clavicle & $110(0.46)$ & $882(3.7)$ & $68(0.29)$ & $63(0.27)$ & $16(0.07)$ \\
\hline \multicolumn{6}{|l|}{ Forearm } \\
\hline Proximal & $74(0.31)$ & $595(2.49)$ & $71(0.3)$ & $61(0.26)$ & $14(0.06)$ \\
\hline Shaft & $14(0.06)$ & $163(0.67)$ & $13(0.06)$ & $4(0.01)$ & $4(0.02)$ \\
\hline Distal & $158(0.67)$ & $1201(5.05)$ & $45(0.19)$ & $59(0.25)$ & $27(0.11)$ \\
\hline \multicolumn{6}{|l|}{ Hand } \\
\hline Carpal & $155(0.62)$ & $1739(7.22)$ & $73(0.31)$ & $50(0.21)$ & $27(0.11)$ \\
\hline Metacarpal & $233(0.92)$ & $1978(8.27)$ & $77(0.33)$ & $66(0.28)$ & $7(0.03)$ \\
\hline Phalanx & $568(2.41)$ & 4669 (19.52) & $189(0.8)$ & 150 (0.626) & $44(0.19)$ \\
\hline \multicolumn{6}{|l|}{ Lower extremity } \\
\hline \multicolumn{6}{|l|}{ Femur } \\
\hline Proximal & $8(0.03)$ & $108(0.43)$ & $10(0.04)$ & $9(0.04)$ & $7(0.03)$ \\
\hline Shaft & $18(0.08)$ & $123(0.5)$ & $6(0.03)$ & $5(0.02)$ & $1(0.00)$ \\
\hline Distal & $4(0.02)$ & $30(0.1)$ & $3(0.01)$ & 0 & $5(0.02)$ \\
\hline \multicolumn{6}{|l|}{ Lower leg } \\
\hline Proximal & $30(0.13)$ & $170(0.7)$ & $25(0.11)$ & $18(0.07)$ & $4(0.02)$ \\
\hline Shaft & $32(0.14)$ & 333 (1.38) & $23(0.09)$ & $24(0.01)$ & $6(0.03)$ \\
\hline Distal & $295(1.22)$ & $2682(11.19)$ & 209 (0.88) & 109 (0.46) & $39(0.16)$ \\
\hline Patella & $31(0.13)$ & $303(1.26)$ & $30(0.13)$ & $25(0.1)$ & $14(0.06)$ \\
\hline \multicolumn{6}{|l|}{ Foot } \\
\hline Tarsal & $98(0.39)$ & $823(3.35)$ & $70(0.3)$ & $40(0.11)$ & $19(0.08)$ \\
\hline Metatarsal & $193(0.81)$ & 1527 (6.34) & $85(0.36)$ & $48(0.2)$ & $14(0.06)$ \\
\hline Phalanx & $195(0.82)$ & $1396(5.87)$ & $86(0.36)$ & $85(0.36)$ & $36(0.15)$ \\
\hline Spine & $9(0.04)$ & $110(0.44)$ & $23(0.09)$ & $6(0.02)$ & $6(0.03)$ \\
\hline Pelvis & $7(0.02)$ & $78(0.31)$ & $8(0.04)$ & $2(0.02)$ & $5(0.02)$ \\
\hline Total & $2,277(9.48)$ & $19,383(80.73)$ & $1,153(4.87)$ & $859(3.58)$ & 309 (1.30) \\
\hline
\end{tabular}

Values are presented as number (\%).

fracture incidence rate of 0.19 per 1,000 person-years. A prior study showed that men and women in the general population had a fracture incidence rates of 11.67 and 10.65 per 1,000 person-years, respectively [5]. According to these results, men in the military population had a higher incidence rate of fractures than men in the civilian population, while women in the military population showed a lower incidence rate than women in the civilian population. Wennergren et al. [6] found that men had a fairly flat incidence curve for proximal and distal tibial 
fractures as they grew older, while women had an increasing incidence of tibial fractures with age; they reported that the tibial fractures that occurred in women tended to be osteoporotic fractures. Considering that the mean age of women in their research was 56.1 years, while the mean age of women in the military population was 33.6 years in the present study, age may be an important factor explaining why women in the military population had a lower fracture incidence rate than civilian women.

Clavicle fractures account for $2.6-10 \%$ of adult fractures [7]. It has also been reported that the incidence of clavicle fractures is $0.29-0.64$ per 1,000 person-years [8]. However, the incidence rate of clavicle fractures among U.S. military personnel was found to be 0.91 per 1,000 person-years, which is higher than the values of previous epidemiological reports. An explanation for this finding is that the relatively young and active group of military personnel have job-related upper extremity demands [9]. The result in our study showed an incidence rate of clavicle fractures of 0.94 per 1,000 person-years, which is similar to the rate reported in the aforementioned study.

Hand injuries are a major cause of working hours lost in both military and civilian settings [10]. Maintaining and handling weapons, using knives, exercise, blunt trauma, and explosions are the main causes of hand injuries in military personnel, resulting in simple lacerations, ligament and nerve injuries, fractures, and amputations [11]. Penn-Barwell et al. [12] reported that hand injuries accounted for $6.5 \%$ of injuries in the military population over the course of 6 years; $15 \%$ were lacerations accompanied by nerve and ligament injuries, and 53\% were fractures. Other research focusing on civilians showed that metacarpal bone fractures accounted for $9.6 \%$, finger fractures for $9.6 \%$, and carpal bone fractures for $2.7 \%$ of 55,953 fracture cases occurring in a 1-year period. In addition, the incidence of thumb and finger fractures has been reported to be 107.3 per 100,000 people in England (UK) [5]. However, in our study, phalanx fractures accounted for $23.5 \%$ of all fracture cases, metacarpal bone fractures for $9.8 \%$, and carpal bone fractures for $8.5 \%$, and the overall thumb and finger fracture incidence was 309.9 per 100,000 people. Therefore, military personnel have a higher incidence rate of finger fractures than civilians. Since phalanx fractures occur more often among military personnel than in the civilian population, military personnel should receive regular safety training and should be equipped with personal protective gear to prevent non-battle-related injuries such as finger injuries.

Dichiera et al. [13] identified that metacarpal fractures most commonly affected men in the 20-24 years age group and that they occurred as a result of assigned duties, training, and self-inflicted activities. Greer [14] reported that $22 \%$ of metacarpal fractures in military personnel occurred in those who were involved in arguments with women and who had consumed alcohol. Previous research has shown that impulsive angry behavior [15] and alcohol consumption [16] are common causes of metacarpal fractures among the civilian population. Our results showed that the metacarpal fractures were the third most common type of fractures in the military population. We did not investigate the causes of metacarpal fractures in this study, but it would be helpful to refer to previous research in order to become aware of the causes.

Military training is commonly cited as a causative factor for musculoskeletal lower limb injuries in military personnel, and this has been well established in the literature [17]. The treatment of lower limb injuries is difficult and costly, as rehabilitation after these injuries is often long-lasting [18], and lower limb injuries during military service are associated with a risk of weakened combat power [19]. Davidson et al. [20] reported data on musculoskeletal lower limb injuries from the entire New Zealand Defence Force for a 1-year period and identified that ankle sprains and knee sprains were common injuries; however, lower limb fractures resulted in costlier treatment and a substantially higher number of working days lost than sprains or contusions. In addition, they reported that fractures of the lower limb accounted for $5.6 \%$ of injuries, while the foot accounted for $41.9 \%$ of fractures; these results are similar to ours. A previous study reported that $9.0 \%$ of all fractures involved the ankle, $6.8 \%$ of all fractures involved the metatarsal bone, and $3.6 \%$ of all fractures involved the phalanx (toe) in the civilian population during a 1-year period [5]. Our results showed a similar proportion of metatarsal bone fractures (7.78\%), but higher proportions of ankle and toe fractures in the military forces $(13.9 \%$ and $7.57 \%$, respectively).

The major limitation of this study is the absence of an 
analysis of causative factors of fractures. There are many causes of fractures that occur in military personnel, including training, broken tools, and explosions, and the precise distribution of types of fractures and fracture sites depends on the causes. Therefore, further studies are needed to identify the causes of different types of fractures and to reduce the risk of fractures during training and duties. This will help reduce the incidence rate of fractures, prevent non-battle-related injuries, and keep the military combat-ready. Further studies are needed to find effective ways of reducing the incidence of non-combat fractures in the Korean military and to compare fracture patterns between Korean and foreign soldiers.

Despite the above limitations, it is worth mentioning that no previous study has investigated the overall incidence and pattern of fractures in the Korean military; therefore, this study makes a meaningful contribution to our knowledge of the incidence of fractures in the Korean military.

\section{CONCLUSION}

This study investigated the population of patients with fractures in the Korean military forces and identified that the most common site for fracture occurrence was the hand, followed by the foot, ankle, and wrist. The types of fractures were further classified, and phalanx (thumb and finger) fractures were found to be the most common. To prevent the loss of combat power due to non-battle-related injuries, thorough preparation is needed, such as protective equipment and preliminary training for fracture areas with a high frequency of occurrence.

\section{REFERENCES}

1. Andersson G, AAoO S. The burden of musculoskeletal diseases in the United States (BMUS). 4th ed. Rosemont (IL):United States Bone and Joint Initiative;2014.

2. Wheeler AR, Wenke JC. Military fractures: overtraining, accidents, casualties, and fragility. Clinic Rev Bone Miner Metab 2018;16:103-15.

3. Owens BD, Mountcastle SB, Dunn WR, DeBerardino TM, Tay- lor DC. Incidence of anterior cruciate ligament injury among active duty U.S. military servicemen and servicewomen. Mil Med 2007;172:90-1.

4. Wolf JM, Dawson L, Mountcastle SB, Owens BD. The incidence of scaphoid fracture in a military population. Injury 2009;40:1316-9.

5. Court-Brown CM, Caesar B. Epidemiology of adult fractures: a review. Injury 2006;37:691-7.

6. Wennergren D, Bergdahl C, Ekelund J, Juto H, Sundfeldt M, Möller M. Epidemiology and incidence of tibia fractures in the Swedish Fracture Register. Injury 2018;49:2068-74.

7. Postacchini F, Gumina S, De Santis P, Albo F. Epidemiology of clavicle fractures. J Shoulder Elbow Surg 2002;11:452-6.

8. Nowak J, Mallmin H, Larsson S. The aetiology and epidemiology of clavicular fractures. A prospective study during a two-year period in Uppsala, Sweden. Injury 2000;31:353-8.

9. Hsiao MS, Cameron KL, Huh J, Hsu JR, Benigni M, Whitener JC, Owens BD. Clavicle fractures in the United States military: incidence and characteristics. Mil Med 2012;177:970-4.

10. Moini M, Rasouli MR, Khaji A, Farshidfar F, Heidari P. Patterns of extremity traumas leading to amputation in Iran: results of Iranian National Trauma Project. Chin J Traumatol 2009;12:7780.

11. Miller MA, Hall BT, Agyapong F, Kelly KJ, McArthur T. Traumatic noncombat-related hand injuries in U.S. troops in the combat zone. Mil Med 2011;176:652-5.

12. Penn-Barwell JG, Bennett PM, Powers D, Standley D. Isolated hand injuries on operational deployment: an examination of epidemiology and treatment strategy. Mil Med 2011;176:1404-7.

13. Dichiera R, Dunn J, Bader J, Bulken-Hoover J, Pallis M. Characterization of metacarpal fractures in a military population. Mil Med 2016;181:931-4.

14. Greer MA. Incidence of metacarpal fractures in U.S. soldiers stationed in South Korea. J Hand Ther 2008;21:137-41; quiz 142.

15. Chung KC, Spilson SV. The frequency and epidemiology of hand and forearm fractures in the United States. J Hand Surg Am 2001;26:908-15.

16. Gudmundsen TE, Borgen L. Fractures of the fifth metacarpal. Acta Radiol 2009;50:296-300.

17. Billings CE. Epidemiology of injuries and illnesses during the United States Air Force Academy 2002 Basic Cadet Training program: documenting the need for prevention. Mil Med 2004;169:664-70. 
18. Parkkari J, Kujala UM, Kannus P. Is it possible to prevent sports injuries? Review of controlled clinical trials and recommendations for future work. Sports Med 2001;31:985-95.

19. Pope RP, Herbert R, Kirwan JD, Graham BJ. Predicting attrition in basic military training. Mil Med 1999;164:710-4.

20. Davidson PL, Chalmers DJ, Wilson BD, McBride D. Lower limb injuries in New Zealand Defence Force personnel: descriptive epidemiology. Aust N Z J Public Health 2008;32:167-73. 